\title{
Neonatal Fc receptor expression in lymphoid and myeloid cells in systemic lupus erythematosus
}

\author{
Yanis Ramdani ${ }^{1}$, Cécile Bergua ${ }^{2}$, Christelle Barbet ${ }^{1}$, François Maillot ${ }^{1}$, Adrien Bigot ${ }^{1}$, \\ Pauline Beurier $^{1}$, Nicole Ferreira-Maldent ${ }^{1}$, Elisabeth Diot ${ }^{1}$, and Valérie Gouilleux-Gruart ${ }^{2}$ \\ ${ }^{1}$ Hôpital Bretonneau \\ ${ }^{2}$ Université François Rabelais Tours
}

November 5, 2020

\begin{abstract}
The neonatal Fc receptor (FcRn) is an ubiquitously-expressed protein historically involved in IgG and albumin recycling. Recent data suggest an involvement in the pathophysiology of antibody-mediated autoimmune diseases. Among them, systemic lupus erythematosus (SLE) implies clinical and biological abnormalities of innate and adaptive circulating immune cells potentially involving newly described functions of FcRn. In this study, FcRn expression was measured by flow cytometry in leukocytes of 41 SLE patients with either active or inactive disease and 32 healthy donors. FcRn expression in B cells, natural killer cells, T cells of SLE patients was statistically lower as compared to healthy donors. Conversely, FcRn levels were statistically higher in non-classical monocyte subpopulation (CD14+CD16+ monocytes) of SLE patients vs. healthy donors. Non-classical monocytes are known to be involved in organ damage in SLE. Thus, the higher expression of FcRn in these cells could support the hypothesis of FcRn participation in the pathophysiology of SLE, especially in lupus nephritis.
\end{abstract}

\section{Hosted file}

FcRn.pdf available at https://authorea.com/users/373422/articles/491121-neonatal-fcreceptor-expression-in-lymphoid-and-myeloid-cells-in-systemic-lupus-erythematosus 


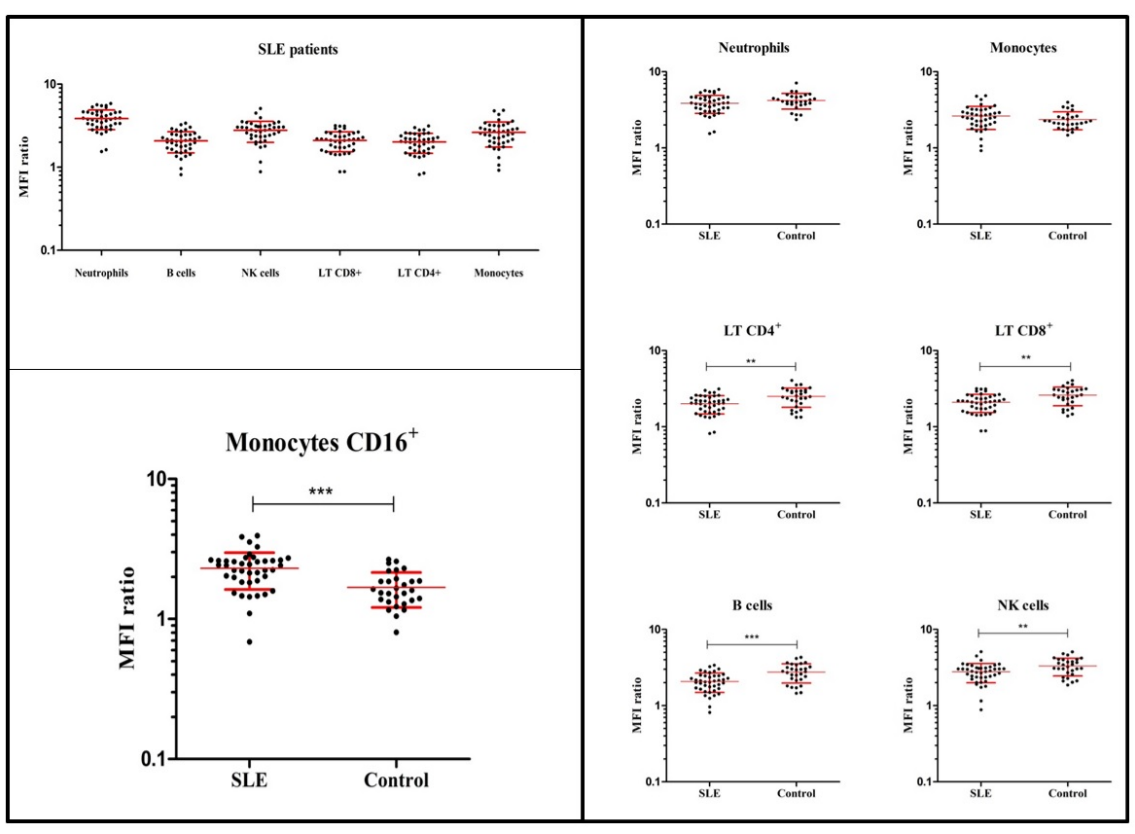

